\title{
The Role of Pre- and Postnatal Timing of Family Risk Factors on Child Behavior at $\mathbf{3 6}$ months
}

\author{
Mona Bekkhus • Michael Rutter • Edward D. Barker • \\ Anne I. H. Borge \\ Published online: 22 December 2010 \\ (C) The Author(s) 2010. This article is published with open access at Springerlink.com
}

\begin{abstract}
Children growing up in disharmonious families with anxious/depressed mothers are at risk for emotional and behavioral difficulties, however whether these associations reflect postnatal environment, prenatal exposure, or an overall liability is still unclear. This study used prospectively collected data from 24,259 participants of the Norwegian Mother and Child Cohort Study (MoBa). Mothers reported on anxiety/depression and family disharmony twice in pregnancy and twice post pregnancy, as well as on their child's physical aggression and crying behavior at age 36 months. First, results from an autoregressive cross-lagged model showed a substantial stability in both maternal anxiety/depression and family disharmony from pregnancy to 18 months postnatal, but there was no indication that family disharmony led to maternal anxiety/depression, or the other way around. Second, structural equation models further suggests that the main risk derived from an overall liability, that is, a lasting effect of family risks that spanned the two time periods.
\end{abstract}

Keywords Maternal anxiety/depression - Crying behavior . Physical aggression · Prenatal

\section{Abbreviations \\ $\mathrm{MoBa}$ The Norwegian Mother and Child Cohort Study}

M. Bekkhus $(\bowtie) \cdot$ A. I. H. Borge

Department of Psychology, University of Oslo,

P.O. Box 1094 Blindern, 0317 Oslo, Norway

e-mail: mona.bekkhus@psykologi.uio.no

\section{Rutter}

Institute of Psychiatry, King's College London,

London, UK

\section{E. D. Barker}

Department of Psychological Sciences, Birkbeck College,

University of London,

London, UK
Children growing up in disharmonious families or who have an anxious/depressed mother are at risk for emotional/ behavioral difficulties (Clarke-Stewart and Dunn 2006; Cummings and Davies 1994). A number of studies suggest that both family dysfunction and maternal anxiety/depression increase emotional and behavior difficulties because they disrupt the mother's ability to care for her child (Ary et al. 1999; Carter et al. 2001; Ewell Foster et al. 2008; Fergusson et al. 1992; Ingoldsby et al. 1999; Johnson et al. 2001). Even very young infants show disruptive behavior when interacting with their anxious/depressed mothers (Field 1995; Field et al. 1990; Weinberg and Tronick 1998). These children are also most likely to have persistent behavior problems, such as aggression at school entry (Barker and Maughan 2009; Campbell et al. 2000; Côtè et al. 2006; Forehand et al. 1998), suggesting the postnatal mediating effect on child adjustment.

To date, studies have largely focused on the role of postnatal family risk. One might think, however, that infants who are exposed to family disharmony or maternal anxiety/depression after birth also have been exposed similarly to the same risks during pregnancy. For example, Hay et al. (2008) found that more than half of the women reporting postnatal depression had been depressed in pregnancy. How often postnatal family disharmony is preceded by prenatal family disharmony, however, is not yet known. The aim of the present paper is to examine the inter-relationships among family risks of maternal anxiety/ depression and family disharmony across the pre- and postnatal period and associations with two key indices of negative behavioral outcomes, disruptive crying and physical aggression. This is potentially important for two rather separate reasons.

First, a number of studies suggest that maternal anxiety/ depression and family disharmony are associated (see e.g. Barker and Maughan 2009; Dickstein et al. 1998; Sameroff 1998). However, to our knowledge there have been no 
previous studies empirically examining the cross-effects of maternal anxiety/depression and family disharmony. One key issue therefore, concerns how these risks "work together". One possibility is that one leads to the other, for example, the influence of parent psychopathology on child behavior problems may be mediated by impaired family functioning and increased family conflicts (Du Rocher Schudlich et al. 2008; Pedersen and Revenson 2005), and mothers reporting higher levels of anxiety and stress have also been found to report lower levels of support from their partner (Dennis and Ross 2006). Thus, alternatively, disharmony may predispose to maternal anxiety/depression.

Second, prenatal exposure to maternal anxiety/depression has been associated with shortened gestation, restricted fetal growth and low birth weight (see e.g. Austin et al. 2005; Rahman et al. 2007; Schneider et al. 2001). There is further a small but growing literature, indicating that prenatal maternal anxiety/depression shapes fetal behavior patterns that persist into the postpartum period, and may have long-term consequences for emotional and behavior development (see e.g. Glover and O'Connor 2002; Gitau et al. 2001; O'Connor et al. 2002; Van den Bergh and Marcoen 2004; Talge et al. 2007). Thus, a second key issue is whether there is a timing effect of family risks stemming from pregnancy.

One possible explanation for this association is suggested to be the mediating mechanism of the hypothalamic-pituitary adrenal (HPA) axis. In humans prenatal stress involves the production of the steroid, cortisol (a glucocorticoid), which may cross the placental barrier and influence fetal growth and brain development that could have long-term developmental consequences (Welberg and Seckl 2001; Weinstock 2008). In contrast to the above findings, however, some researchers have not found any link between prenatal maternal anxiety/ depression and later emotional and behavior problems (DiPietro et al. 2006; Kim-Cohen et al. 2005). Thus the strength of this association is far from clear. On the one hand, these uncertainties may be related to methodological problems such as failure to include covariates (McIntosh et al. 1995), low sample size (Van den Bergh and Marcoen 2004), only reporting one time-point in pregnancy (Davis et al. 2004), or failure to adequately account for postnatal experiences. Traditionally, this has been dealt with by treating postnatal exposure as a possible confounder (e.g. O'Connor et al. 2002), rather than making direct comparisons. On the other hand, it may be the case that the association between family risks and later emotional and behavior problems is equally related to both the pre- and postnatal exposure. That is, whether there is a risk effect of a liability to maternal anxiety/depression or family disharmony over time that constitute an enduring risk for the disruptive behavior of crying and aggression in the child.

In light of this background, the current study has two aims. The first aim was to examine the inter-relationships between two known risks within the family, by two contrasting hypotheses: (1) Increase in subsequent symptoms of maternal anxiety/depression is a function of prior family disharmony vs. (2) increase in family disharmony is a function of prior symptoms of maternal anxiety/depression.

The second aim was to examine the prenatal, postnatal and overall liability to family disharmony and maternal anxiety/ depression on child behavior. An "overall liability" would suggest that there is an enduring risk effect, stemming from both the pre- and postnatal period. Thus, three contrasting hypotheses were examined: (1) Crying and physical aggression in 3 year olds are a function of a prenatal exposure to family risks vs. (2) a function of a postnatal exposure to family risks vs. (3) a function of an overall liability in which there is no marked time-specific effect.

\section{Method}

Participants

This study is based on the Norwegian Mother and Child Cohort Study (MoBa) conducted by the Norwegian Institute of Public Health (Magnus et al. 2006; Nilsen et al. 2009). In brief, MoBa is a cohort consisting of more than 100000 pregnancies recruited from 1999 to 2009. The majority of all pregnant women $(70 \%)$ in Norway were invited to participate, and participants were recruited to the study through a postal invitation in connection with a routine ultrasound examination offered to all pregnant women in Norway at 17-18 weeks of gestation (www.fhi. no/morogbarn). In addition data were also drawn from the Medical Birth Registry of Norway (MBRN), which contains data on all births in Norway. The current study is based on version IV of the quality-assured data files for participants recruited in the period of 1999 to 2006. At this time of recruitment about 28,897 children had reached the age of 3-years. Informed consent was obtained from each participant. The study was approved by The Regional Committee for Medical Research Ethics and the Norwegian Data Inspectorate.

\section{Measures}

Crying Behavior Crying behavior was measured by three items ("cries easily", "gets upset or sad easily", "reacts intensely when upset") on a five-point response-scale from very typical to not typical. These items were taken from the emotionality subscale of the EAS temperament questionnaire (Buss and Plomin 1984; Mathiesen and Tambs 1999). Items were coded so that higher scores reflected more crying behavior. The total score ranged from 0 to 12 , with $M=5.34$, $\mathrm{SD}=2.3$. Cronbach's alpha was 0.64. Model fit from CFA 
was good $\left(\chi^{2}(\mathrm{df}=0) 0 ;\right.$ CFI 1.0; TLI $=1.0 ;$ RMSEA $\left.=0.00\right)$, and factor loadings ranged from 0.47 to 1.0 .

Physical Aggression Physical aggression was taken from the externalizing subscale of the Child Behavior Check List (CBCL/1.5-5) (Achenbach et al. 1987). Included items were "becomes aggressive when he/she is frustrated", "gets in many fights", "hits others", "tests other children to see whether they get angry", "hits, shoves, kicks and bites other children". These items were rated by mothers on a threepoint scale and were coded so that more aggressive behavior reflected higher scores. The total score ranged from 0 to 10 with $M=1.7, \mathrm{SD}=1.7$, Cronbach's alpha was 0.93. Model fit from CFA was adequate $\left(\chi^{2}(\mathrm{df}=5)=724.6\right.$; CFI 0.97; TLI=0.93; RMSEA=0.07), with factor loadings ranging from 0.50 to 0.69 .

Maternal Anxiety/Depression Maternal anxiety/depression (SCL) was measured by 5 items, on a four-point scale from not bothered (0), to very bothered (3) from the Hopkins Symptom Checklist (Tambs and Moum 1993). The mothers were asked if they had experienced the following in the last 2 weeks, ("constantly afraid and anxious"; "nervous, inner turmoil"; "hopelessness"; "depressed"; "worries or restless"). The total score was computed from the means of these 5 items, and ranged from 0 to 15 , with $M=1.14, \mathrm{SD}=1.8$ at $17 \mathrm{w}, M=1.15, \mathrm{SD}=1.8$ at $30 \mathrm{w} . M=1.08, \mathrm{SD}=1.8$ at 6 months postpartum, and $\mathrm{M}=1.36, \mathrm{SD}=2.0$ at 18 months postpartum. Cronbach's alphas for 17th, 30th week and 6 months and 18 months were $0.80,0.83,0.85,0.85$ respectively.

Family Disharmony Family disharmony was measured at all assessment points by ten items (e.g., "closeness to partner"; "relationship problems") (Blum and Mehrabian 1999). The items were measured on a response scale from I completely agree (0) to I completely disagree (5), and were coded so that higher score reflected greater disharmony. The total score was computed by the mean of all items ranging from 0 to 50 , with $M=6.76, \mathrm{SD}=6.2$ at $17 \mathrm{w}, M=$ $6.46, \mathrm{SD}=6.1$ at $30 \mathrm{w} . \quad M=7.26, \mathrm{SD}=6.9$ at 6 months postpartum, and $M=8.13, \mathrm{SD}=7.6$ at 18 months postpartum. Cronbach's alphas for 17th, 30th week and 6 months and 18 months were $0.91,0.91,0.92,0.93$ respectively.

Maternal Characteristics Age at time of birth was gathered from Medical Birth Registry of Norway (MBRN), and ranged from 14 to $47, M=30.2, \mathrm{SD}=4.4$. Marital status was coded as ' 0 ' married/living together $(97.3 \%)$, or ' 1 ' unmarried/single. Education was assessed at the first assessment and coded into four rank-order scales so that a low score reflected high education, and a high score indicated low education, from university/college of 4 years or more (0), university/college of up to 4 years (1), high school up to the age of 18-19 (2), to secondary school up to the age of 15-17 (3), with an average of up to 4 years in university/college $(M=1.2, \mathrm{SD}=0.85)$. Family income was collected separately for mothers and fathers, ranging from no income (1) to more than 500,000 NOK a year (7) (about 90 100,000 US dollars). The total family income was computed by summating both maternal and father income, and ranged from 1 to 14 , from no income to more than 1 mill NOK/ 200,000 US dollar a year. A higher score indicated higher family income, with $M=8.4, \mathrm{SD}=2.3$, equal to an average of 500,000 NOK/90-100,000 US dollar a year.

Exposure in Pregnancy Smoking was extracted from the Medical Birth Registry of Norway (MBRN), using a standardized notification form in which women were asked whether they smoked during pregnancy. Non-smokers were coded as ' 0 ' (78.7\%), and those who smoked occasionally or daily as ' 1 ' (10.1\%) (Missing=11, 2\%), $M=0.11, \mathrm{SD}=0.32$. Alcohol consumption during pregnancy was measured at the 17th week of gestation. The mothers were asked if they had had 5 units of alcohol ( 1 unit $=1.5 \mathrm{cl}$ pure alcohol), or more per occasion in this pregnancy, ranging from never to less than once a month to several times a week. This variable was treated as a dummy variable reflecting those who never drank, or drank less than once a month (0), and those who reported that they drank several times a month or more (1), $(M=0.01, \mathrm{SD}=0.08)$.

Child Characteristics Gender was coded as '0' girls (49.2\%), and ' 1 ' for boys (50.8\%). Low birth weight was extracted from the MBRN, and was coded as yes (1) if the infant weighted $\leq 2,500 \mathrm{~g}$ or less and no (0) if the infant weighted more than $>2,500 \mathrm{~g}, M=0.03, \mathrm{SD}=0.16$. Head circumference was coded as a dummy variable, with either smaller than $\leq 33$, (0), or above $\geq 34$ (1), $M=0.90, \quad \mathrm{SD}=30$. Birth complications were answered by the mothers at 6 months and were coded as (1) if yes, and (0) if no, $M=0.18, \mathrm{SD}=$ 0.38 . Caesarean sections were extracted from the MBRN and coded as (1) if yes, and (0) if no, $M=0.12, \mathrm{SD}=0.33$.

\section{Attrition Analyses}

The participation rate at study commencement was $42.7 \%$ (Magnus et al. 2006), and response rates for the 17th and 30th weeks of gestation, and 6th, 18th and 36th months postnatal were $95.3 \%, 92.7 \%, 91.5 \%, 74.4 \%$, and $61.4 \%$ respectively. Thus, as is the case in many longitudinal studies there is the concern that those participants differ systematically from those not participating. This concern has been thoroughly examined by Nilsen et al. (2009) who compared the MoBa participants with data from the Medical Birth Registry of Norway (MBRN), which has 
information on all women giving birth in Norway. They found evidence for selection bias in prevalence rates that may have relevance to interpretation of the findings in the current study. The MoBa study had lower participation of the youngest mothers $(<25$ years), those living alone, and those mothers with more than two previous births. These biases were small in number, but will inevitably somewhat reduce the prevalence rate of risk. This does not, however, mean that the pattern of correlations with other variables will be biased. For bias to arise would require that the pattern of associations differed between those participants with the key characteristic in the study and those not. In other words, bias would arise only if (for example) younger mothers who participated had a different pattern of associations from younger mothers who did not. Although possible, that is unlikely and the evidence suggests that this rarely happens. Nilsen et al. (2009) found that many associations between exposure variables and outcomes were the same in the MoBa study and the comparison of the Norwegian registry. Similarly an analysis was undertaken by Wolke et al. (2009) with respect to selective dropout in the Avon Longitudinal Study of Parents and Children (ALSPAC). As in MoBa, it was found that those who dropped out from the study were more likely to suffer from disruptive behavior disorders and, hence, this would inevitably bias prevalence rates. By contrast, systematic participant drop-out did not alter the association between family variables obtained in pregnancy and disruptive behavior disorder at 8 years of age. Both the empirical findings and a range of simulations confirm that the validity of regression models was only very marginally affected despite range restrictions after selective drop-out.

Furthermore, for the MoBa study, additional analyses were undertaken by comparing the $61.4 \%$ who returned the questionnaire at 36 months with the remaining $38.7 \%$, in terms of data available at the first assessment using Chi-square difference test and $t$-test for the continuous measures. There were no significant differences in terms of gender, birth complications, or low birth weight. However, a very small difference was found for caesarean sections $(13.9 \%$ in the total sample, vs. $13.0 \%$ in the present sample, $p=0.001)$. No major differences were found for the demographic variables (maternal education, marital status, maternal age and family income) or family risk variables (maternal anxiety and family disharmony), with mean differences varying from 0.18 to 0.56 . The effect sizes for these differences were all very low (Cohen's $d=0.08$ to 0.21 ). Nevertheless, with this very large sample size, these minor differences were statistically significant. The effect sizes, however, were very small and it is unlikely that these proportions in prevalence would affect the associations. Missing a disproportionate number of individuals with high-risk characteristics, as was the case here, may affect prevalence rates of both the risks and the outcomes for which they provide a risk. However, that is not the focus of the current paper. The present study is concerned with patterns of associations. Accordingly, even with a missing proportion of high-risk individuals, there can be no necessary expectation that this will affect the associations with other variables.

For the present study, information was available for 24,677 children for whom complete information on all time points were available. The present sample comprised 24,259 children, after multiple births were excluded $(N=418)$.

\section{Statistical Analyses}

The analytic strategy followed three steps using Mplus version 5.1 (Muthén and Muthén 2007). Full information maximum likelihood was used to account for missing data. Model fit was determined by Chi-square estimates, the comparative fit index (CFI, critical value _ 0.90) (Bentler and Bonett 1980), the Tucker Lewis Index (TLI, critical value _ 0.90) (Little et al. 2003) and the root mean squared estimate of approximation (RMSEA, critical value _ 0.08 ) (Browne and Cudeck 1993).

In the first step, we examined the inter-relationship between the independent and dependent variables. Because of the potentially important relationship between the two risks, the first step needed to start by examining the associations between maternal anxiety/depression and family disharmony, using an autoregressive model. Cross-lagged paths were included in the model to account for possible influences of high levels of maternal anxiety/depression on family disharmony (and viceversa). The stability of maternal anxiety/depression and of family disharmony were examined by regressing scores at 17 weeks (for example) on their immediate prior values (autoregressive part). Finally we estimated the path from these risks on crying behavior and physical aggression.

In the second step, the latent factors of maternal anxiety/ depression and family disharmony were constructed. This step consisted of two main parts, one measurement model and one path model (McDonald and Ho 2002). The first models, the Confirmatory Factor Analyses (CFA), are shown in the appendices and were used in order to evaluate the latent structure of maternal anxiety/depression and family disharmony measured at each of the four time-points, with observed variables as indicators of the latent variables and with the error terms correlated across time. Thus, the first set of analysis focused on four separate CFA models, one for each time point, so that maternal anxiety/depression was constructed from five indicators (and family disharmony by 10 indicators) at each time point. Then these CFA models (Appendix A) represented the primary factors of the second order factor of the latent structure prenatal-only (at 17th and 30th week of gestation) and the latent structure of postnatal-only (at $6 \mathrm{~m}$ and $18 \mathrm{~m}$ ). In the second step, a path model was added in order to examine the relative impact of these latent constructs, of the 
prenatal-only and the postnatal-only, on crying behavior and physical aggression, after adjusting for a range of possible confounders reflecting child characteristics, birth characteristics, socio-demographics and maternal characteristics.

The third step of our analytic strategy also consisted of two main parts, one measurement model and one path model. The first set of analyses focused on four separate CFA models as described in step two. These CFA models represented the second order factor "overall liability" of either maternal anxiety/depression or family disharmony (Appendix B). In the second part of the structural model, the path model, we estimated the relative impact of the overall liability of maternal anxiety/depression and family disharmony on physical aggression and crying behavior, after adjusting for potential confounders.

Equally, the latent structures of child behavior were first computed by combining the two outcomes, and second by constructing a latent variable of each child outcome, we report the latter based on factor loadings and a comparison between model fit for the different models.

\section{Results}

Step 1: Autoregressive Cross-Lagged Model of Maternal Anxiety/Depression and Family Disharmony

Maternal anxiety/depression and family disharmony from early pregnancy ( 17 weeks) through late pregnancy ( 30 weeks), 6 and 18 months postnatal (see Fig. 1) showed stability, with path coefficients in the range from 0.3 to 0.7 . The implication that maternal anxiety/depression may influence family disharmony or vice versa (cross-lagged part), was not supported. The path coefficients, although statistically significant were all very low (in the range of 0.03 to 0.07 ). There was also a small effect for maternal anxiety/depression at time 4, on crying behavior and physical aggression (with path coeffi- cients of 0.05 to 0.06$)$. The contemporaneous correlations between the two predictors were moderate $(r=0.20$ to 0.30$)$, as were they also between the two outcomes $(r=0.38)$.

Step 2: The Effect of Prenatal and Postnatal Family Risk

Postnatal maternal anxiety/depression was associated with increased physical aggression $(\beta=0.19, p<0.001)$ and crying behavior $(\beta=0.13, p<0.001)$. However, prenatal maternal anxiety/depression was not significant for either physical aggression $(\beta=-0.003, p=0.92)$, or crying behavior $(\beta=0.04, p=0.087)$ (model fit: $\chi^{2}(\mathrm{df}=598)=17,393.9$; CFI 0.93; TLI=0.92; RMSEA=0.033) (See Fig. 2).

Postnatal family disharmony was associated with increased physical aggression $(\beta=0.14, p<0.001)$ and crying behavior $(\beta=0.14, p<0.001)$, whereas prenatal family disharmony $\mathrm{did}$ not have a significant effect $(\beta=0.01, p=0.55)$ on physical aggression, but showed a small negative effect on crying behavior $(\beta=-0.04, p=0.02)$ (model fit: $\chi^{2}(\mathrm{df}=1,010)=$ 26,618.15; CFI 0.97; TLI=0.96; RMSEA=0.034) (see Fig. 3).

\section{Step 3: The Effect of an "Overall Liability"}

The latent structure combining maternal anxiety/depression across time 1, 2, 3 and 4 had a larger effect on crying behavior $(\beta=0.17, p<0.001)$, as compared with the main effect in step 1 and 2 . The main effect on physical aggression $(\beta=0.18, p<0.001)$, was similar to the postnatal effect (model fit: $\chi^{2}(\mathrm{df}=619)=18,440.9$; CFI 0.93; TLI= 0.92 ; RMSEA $=0.03$ ). These effects were robust and remained after taking account of confounders (Fig. 2).

Similarly the latent structure combining family disharmony across time 1, 2, 3 and 4 had a robust main effect on both crying behavior $(\beta=0.11, p<0.001)$ and physical aggression $(\beta=0.16, p<0.001)$ (model fit: $\chi^{2}(\mathrm{df}=1,553)=$ 34,333.14; CFI 0.96; TLI=0.96; RMSEA $=0.03$ ), which remained after control for confounders (Fig. 3).

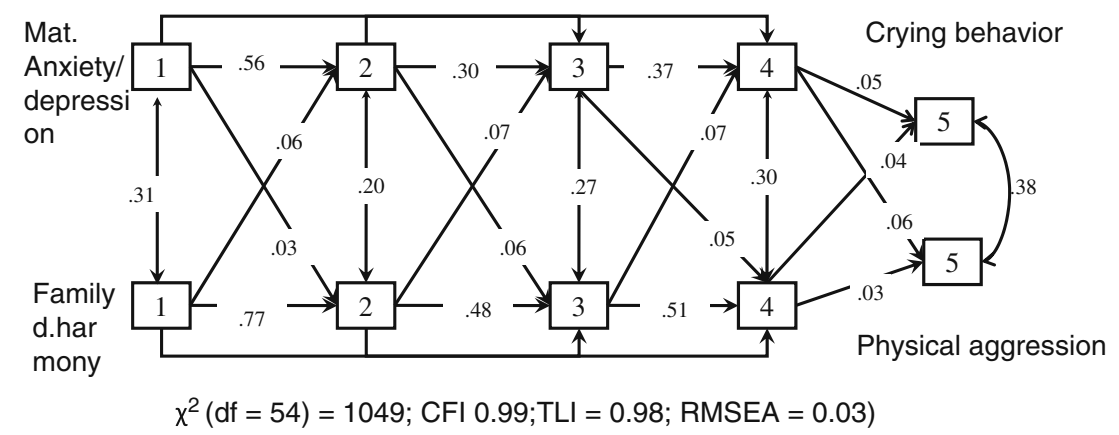

Fig. 1 Adjusted autoregressive cross-lagged model for child behavior 36 months. Associations between maternal anxiety/depression and family disharmony across the pre- and postnatal period and associations with child behavior. Squares represent the observed variables measured at each time-point, $1=17 \mathrm{w}$ of gestation; $2=30 \mathrm{w}$ of gestation; $3=6 \mathrm{~m}$ post partum; $4=18 \mathrm{~m}$ post partum; $5=36$ months child outcome. Standardized estimates are presented as girl/boy when different. The estimated associations are shown by one-sided arrows representing the regression coefficients, and double-sided arrows representing the correlations. All estimates are significant at $p<0.001$ level 


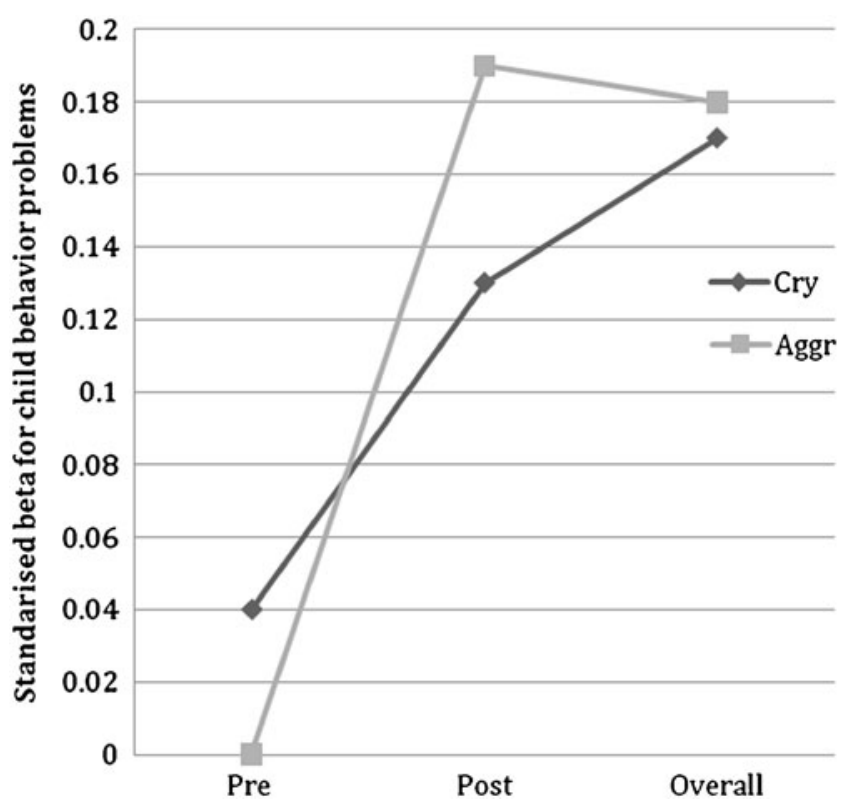

Fig. 2 Pre-post and overall effect of maternal anxiety/depression on child behavior 36 months. Standardized beta coefficients for the associations between the prenatal-only, the post natal-only and the "overall" latent construct of maternal anxiety/depression and the latent constructs of crying behavior and physical aggression at 3 years of age

To summarize, an overall liability of maternal anxiety/ depression was found to have a substantial effect on both crying behavior and physical aggression. It seems likely that the liability of the family risks over time was driving the effect of both crying behavior and physical aggression. Although,

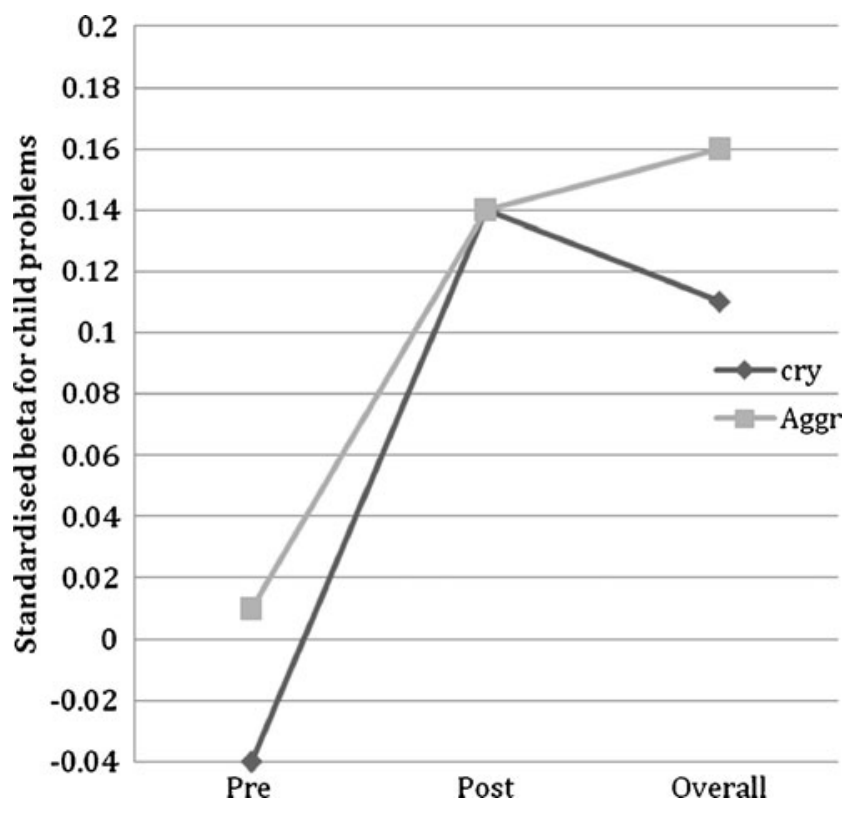

Fig. 3 Pre-post and overall effect of family disharmony on child behavior 36 months. Standardized beta coefficients for the associations between the prenatal-only, the post-natal only and the "overall" latent construct of family disharmony and the latent constructs of crying behavior and physical aggression at 3 years of age these effects are robust we also note those confounders that were found to be associated with child behavior in Table 1 .

\section{Discussion}

Using a large population based longitudinal cohort-study we assessed the relative impact of pre- and postnatal family disharmony and maternal anxiety/depression on children's emotional/behavioral problems within a structural equation model framework. Three findings stand out.

First, there was substantial continuity in maternal anxiety/depression from pregnancy to 18 months after birth, and an even stronger continuity for family disharmony (Fig. 1). This finding supports the assumption that prenatal influences are strongly associated with comparable postnatal experiences (Hay et al. 2008), and suggest that the effects of maternal anxiety/depression and family disharmony represent a risk for children's maladjustment that extends across the pre- and postnatal period.

Second, there was no indication that family disharmony led to maternal anxiety/depression, or the other way around. That is, despite the substantial continuity over time in both family disharmony and maternal anxiety/depression, and despite the contemporaneous association between the two predictors, the cross-lagged correlations and the effects from time 4 on child outcome were all very low (in the range of 0.03 to 0.07 ). One possible explanation is that the very low cross-lagged effects are caused by shared method variance. This is unlikely, however, because the cross-sectional correlations and the associations across time range from low to moderately high, and thus are far from unity. This finding is consistent with the literature suggesting that maternal anxiety/depression may cooccur with family disharmony, but adds to the literature in showing that neither was causal of the other.

Third, although the postnatal effect of both family disharmony and maternal anxiety/depression were substantial compared to the prenatal effects, the main risk effects on crying behavior and physical aggression were the constructs representing an overall liability to maternal anxiety/depression and to family disharmony. The implication is that family influences play a significant role in children's emotional and behavior functioning. Our finding suggesting that family risks may constitute an enduring risk, rather than a marked time-specific effect, was further confirmed by additional follow-up analysis, which showed no difference in effects when we compared 6 months with 18 months, suggesting that some overall liability was involved. Similar to prior studies (e.g. Ewell Foster et al. 2008; Kim-Cohen et al. 2005), our finding suggests that there is no effect of prenatal risks, once postnatal effects are adequately accounted for. It should be noted, however, that this does not rule out the possibility for a prenatal effect on 
Table 1 Significant confounders of crying behavior and physical aggression

\begin{tabular}{|c|c|c|c|c|}
\hline \multirow[t]{2}{*}{ Confounders } & \multicolumn{2}{|c|}{ Crying Behavior $36 \mathrm{~m}$} & \multicolumn{2}{|c|}{ Physical Aggression 36 m } \\
\hline & $\beta$ & $p$-value & $\beta$ & $p$-value \\
\hline Gender & -0.03 & $<0.001$ & 0.14 & $<0.001$ \\
\hline \multicolumn{5}{|l|}{ Birth Characteristics } \\
\hline Low birth weight & - & ns & 0.02 & $<0.001$ \\
\hline \multicolumn{5}{|l|}{ Maternal Characteristics } \\
\hline Smoking in pregnancy & - & ns & 0.03 & $<0.001$ \\
\hline Maternal age & 0.06 & $<0.001$ & 0.06 & $<0.001$ \\
\hline Marital status & 0.05 & $<0.001$ & 0.03 & $<0.001$ \\
\hline Maternal education & 0.03 & $<0.001$ & 0.03 & $<0.001$ \\
\hline \multicolumn{5}{|l|}{ Family Characteristics } \\
\hline Family income & - & ns & 0.03 & $<0.001$ \\
\hline Number of siblings & 0.5 & $<0.001$ & - & ns \\
\hline
\end{tabular}

Note. $\beta=$ Standardized beta coefficient

different child outcomes such as hyperactivity (Bekkhus et al. 2010), or the possibility of a genetic confound.

The main clinical implication of the study findings is that there would be no point in a time-specific intervention, because no time-specific effects were found. Rather, interventions will need to take account of the evidence of an ongoing risk that extends across the prenatal and postnatal age periods. The findings also show that the occurrence of both family disharmony and maternal anxiety/depression are independently important, and that effective interventions are likely to require a focus on both types of risks. Whilst it is tempting to argue that early interventions that target these risks might be beneficial, caution is called for because of two separate considerations. First, the analyses undertaken so far cannot differentiate between environmental mediation and genetic mediation of the risks. Second, until a further follow up has been undertaken (as is currently underway) there is no means of assessing the psychopathological importance of crying and physical aggression in the early years. These findings are important in showing the characteristics of the patterning of risks over time and these suggest that a consideration of clinical implications will be important but, equally, they indicate that it would be premature to advocate interventions at this point.

Our investigation of possible prenatal effects has shown important advantages over previous research and provides new empirical knowledge on some of the potential mechanisms involved in understanding the inter-relationship among pre- and postnatal family risks and emotional/behavior problems in early childhood. First, we had two data points each for both prenatal and postnatal risk factors, thereby increasing the robustness of our measures. Second, we used structural equation modeling, allowing for an estimation of the relations between constructs that are corrected for biases attributable to random error and construct-irrelevant variance (Tomarken and Waller 2005). Third, we had longitudinal data that showed strong continuities over time for both maternal anxiety/depression and family disharmony. This finding suggests little support for there being an independent prenatal effect of either family disharmony or maternal anxiety/ depression on the two outcomes measured in this sample. In addition, the use of a longitudinal design provides measures of the mothers prior to those of the child, which makes it unlikely that the child features caused the family risks. Fourth, we had data on crying behavior (emotionality) and aggression (behavior problems) at a very early age with the possibility for future follow-ups in later phases of the MoBa. To date, very little is known about these behaviors at an early age and how they relate to behavior later on (Gardner and Shaw 2008). Against that background, five key limitations need to be noted.

First, because of the focus on pregnancy and the infancy period all measures were obtained from the same informantthe mother. This is unavoidable when investigating behavior in very young children within large-scale population cohort studies, and is a common feature for similar studies (see e.g. The Avon Longitudinal Study of Parents and Children; Quebec Longitudinal Study of Child Development). The use of self-report and maternal reports for child behavior means that there is the likelihood of halo effects in ratings, reflecting a shared method variance. This means that the estimates of temporal stability or risk factors may be over-estimates. It also means that the associations between risk variables and child outcomes cannot be assumed to be causal. That is, maternal reports of crying behavior or aggression are subjective and therefore their levels of stress during the pre- and postnatal period could affect their perceptions of child crying or aggression (Talge et al. 2007). Thus, there is the possibility that mothers, to some degree, over interpret e.g. their child's behavior as aggressive, when in fact their behavior reflects normal aggression for that age group. Thus, the use of more indepth interviews, or data from other informants would provide 
a better understanding of the mechanisms involved in children's development. Future follow-ups within the MoBa provide the opportunities for sub studies with in-depth interviews and teacher ratings when the children reach school age. However, maternal ratings have been found to show moderate agreement with teacher ratings (Hay et al. 2008; Leblanc et al. 2008; Romano et al. 2006), and mothers are often assumed to provide the most accurate information about their child's emotional and behavior functioning (Phares 1997).

Second, at the time MoBa was planned, measures for the early years of childhood concentrated on temperamental features. Therefore we had only a limited number of items available representing subscales from the CBCL (CBCL/1.55) externalizing scale, and the EAS temperament scale. The selected items, however, were based on a consensus among specialists in clinical and developmental psychology, and our analysis showed an adequate model fit when CFA-models were estimated, as well as acceptable Cronbach's alphas similar to those obtained in other studies for this age group (Côtè et al. 2008; O'Connor et al. 2002; van Zeijl et al. 2006).

Third, our findings extend only to age 3 years. MoBa has further follow-up planned for ages 5 and 7 years and these will provide a broader measurement of internalizing and externalizing psychopathology.

Fourth, we did not have available measures to control for possible genetic confounders, thus whether children exposed to pre- and postnatal family risks are at greater risk due to a genetic vulnerability, is uncertain. However, biological meas- ures that might illuminate possible genetic confounders, may be available in later studies of the MoBa.

We also note that the participation rate in $\mathrm{MoBa}$ at the first assessment was $42.7 \%$. Such proportions are usual in large, general population studies of this kind (see e.g. Nohr et al. 2006; Wolke et al. 2009), but inevitably they raise the possibility of bias. Missing a disproportionate number of high risk individuals may affect prevalence rates. However, the present study focus on patterns of associations and Nilsen et al. (2009) found that these do not differ, despite lower participation of these marginal groups.

\section{Conclusion}

There were substantial continuities between maternal anxiety/depression and family disharmony in the prenatal period and comparable measures in the postnatal periods. The main effect of both family risks was, however, not due to a prenatal effect or a marked time-specific effect, but rather a liability associated with family risk.

Acknowledgements The research is funded by grant $185710 /$ V50 and 154528/330 from the Norwegian Research Council, Norway and a grant for international collaboration from the University of Oslo.

The Norwegian Mother and Child Cohort Study is supported by the Norwegian Ministry of Health, NIH/NIEHS (grant no NO 1-ES-85433), NIH/NINDS (grant no. 1 UO1 NS 047537-01), and the Norwegian Research Council/FUGE (grant no. 151918/S10).

\section{Appendix A}

Fig. 4 CFA model of pre- and postnatal maternal anxiety/ depression. Standardized factor loadings for the second order confirmatory factor analysis of prenatal-only and postnatal-only maternal anxiety/depression, measured by five items at the 17 th week and 30 th week of gestation and at 6 and 18 months postnatal

$$
\begin{aligned}
& \text { Model fit: } \\
& \left(\chi^{2}(\mathrm{df}=135)=10118.5\right. \text {; CFI 0.95; TLI = 0.93; RMSEA = 0.05). }
\end{aligned}
$$

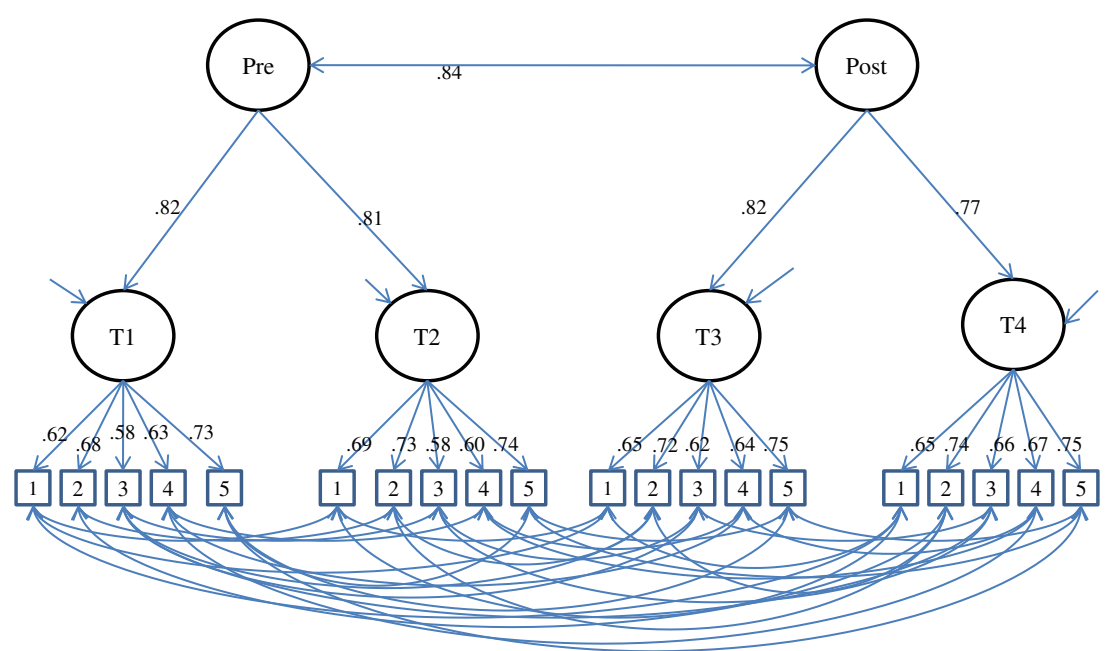


Model fit:

$\left(\chi^{2}(\mathrm{df}=675)=21460 ;\right.$ CFI 0.97; TLI = 0.97; RMSEA $\left.=0.05\right)$.

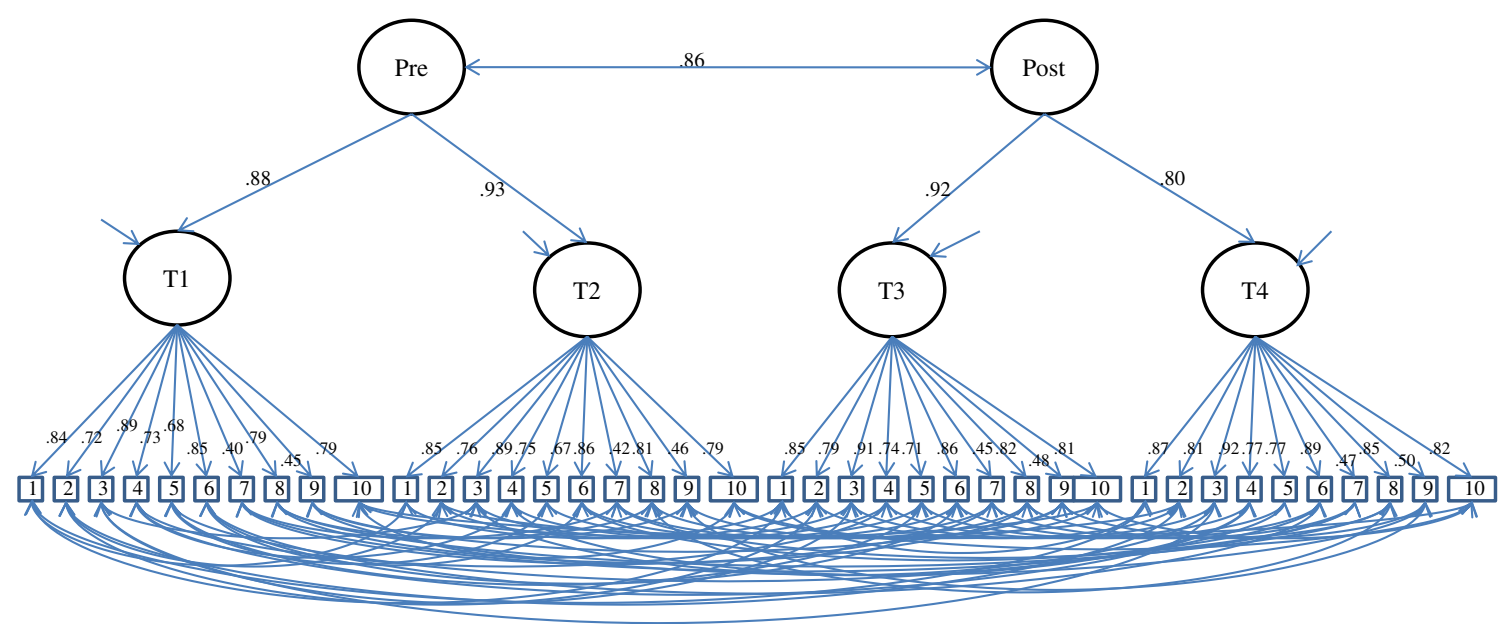

Fig. 5 CFA model of pre- and postnatal family disharmony. Standardized factor loadings for the second order confirmatory factor analysis of prenatal-only and postnatal-only family disharmony measured by ten items at the 17 th week and 30 th week of gestation and at 6 and 18 months postnatal

\section{Appendix B}

Fig. 6 CFA model of overall maternal anxiety/depression. Standardized factor loadings for the second order confirmatory factor analysis of overall maternal anxiety/depression, measured by five items at the 17 th week and 30 th week of gestation and at 6 and 18 months postnatal
Model fit:

$\left(\chi^{2}(\mathrm{df}=136)=10996.5 ;\right.$ CFI 0.94; TLI $=0.92 ;$ RMSEA $\left.=0.05\right)$.

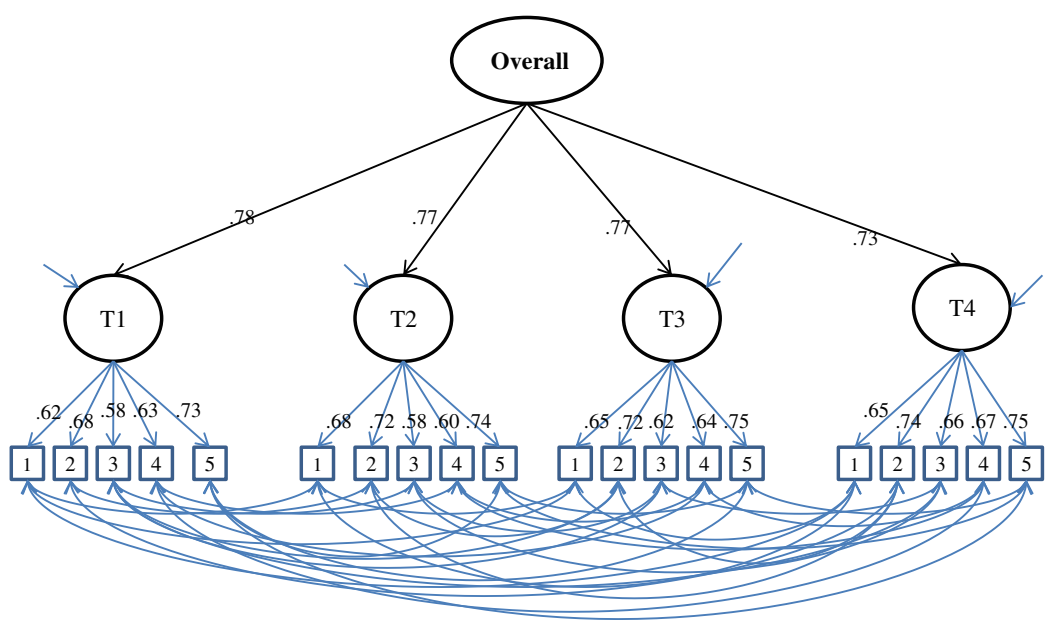


Model fit:

$\left(\chi^{2}(\mathrm{df}=675)=24111.7 ;\right.$ CFI 0.97; TLI $=0.96 ;$ RMSEA $\left.=0.04\right)$.

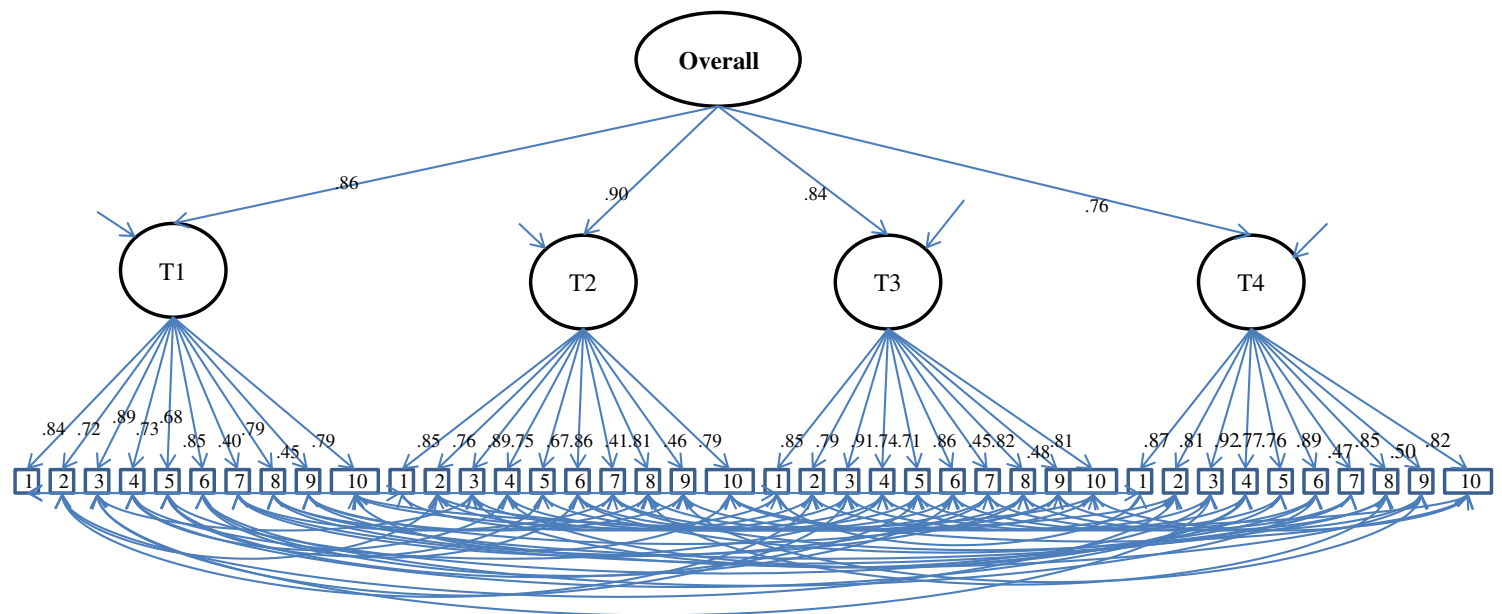

Fig. 7 CFA model of overall family disharmony. Standardized factor loadings for the second order confirmatory factor analysis of overall family disharmony measured by ten items at the 17th week and 30th week of gestation and at 6 and 18 months postnatal

Open Access This article is distributed under the terms of the Creative Commons Attribution Noncommercial License which permits any noncommercial use, distribution, and reproduction in any medium, provided the original author(s) and source are credited.

\section{References}

Achenbach, T. M., Edelbrock, C., \& Howell, C. T. (1987). Empirically based assessment of the behavioral/emotional problems of 2- and 3-year-old children. Journal of Abnormal Child Psychology, 15, $629-650$.

Ary, D. V., Duncan, T. E., Biglan, A., Metzler, C. W., Noell, J. W., \& Smolkowski, K. (1999). Development of adolescent problem behavior. Journal of Abnormal Child Psychology, 27, 141-150.

Austin, M.-P., Leader, L. R., \& Reilly, N. (2005). Prenatal stress, the hypothalamic-pituitary-adrenal axis, and fetal and infant neurobehavior. Early Human Development, 81, 917-926.

Barker, E. D., \& Maughan, B. (2009). Differentiating early-onset persistent versus childhood-limited conduct problem youth. The American Journal of Psychiatry, 166, 900-909.

Bekkhus, M., Skjothaug, T., Nordhagen, R., \& Borge, A. I. H. (2010). Intrauterine exposure to caffeine and inattention/overactivity in children. Acta Paediatrica, 99, 925-928.

Bentler, P. M., \& Bonett, D. G. (1980). Significance tests and goodness of fit in the analysis of covariance structures. Psychological Bulletin, 88, 588-606.

Blum, J., \& Mehrabian, A. (1999). Personality and temperament correlates of marital satisfaction. Journal of Personality, 67, 93-125.

Browne, M. W., \& Cudeck, R. (Eds.). (1993). Alternative ways of assessing model fit. Newbury Park: Sage.

Buss, A. H., \& Plomin, R. (1984). Temperament: Early developing personality traits. Hillsdale: Erlbaum.

Campbell, S. B., Shaw, D. S., \& Gilliom, M. (2000). Early externalizing behavior problems: toddlers and preschoolers at risk for later maladjustment. Development and Psychopathology, 12, 467-488.
Carter, A. S., Garrity-Rokous, F. E., Chazan-Cohen, R., Little, C., \& Briggs-Gowan, M. J. (2001). Maternal depression and comorbidity: predicting early parenting, attachment security, and toddler social-emotional problems and competencies. Journal of the American Academy of Child and Adolescent Psychiatry, 40, $18-26$.

Clarke-Stewart, A., \& Dunn, J. (Eds.). (2006). Family counts. Effects on child and adolescent development. Cambridge: Cambridge University Press.

Côtè, S. M., Vaillancourt, T., LeBlanc, J. C., Nagin, D. S., \& Tremblay, R. E. (2006). The development of physical aggression from toddlerhood to pre-adolescence: a nation wide longitudinal study of Canadian children. Journal of Abnormal Child Psychology, 34, 71-85.

Côtè, S. M., Borge, A. I. H., Geoffroy, M.-C., Rutter, M., \& Tremblay, R. E. (2008). Nonmaternal care in infancy and emotional/ behavioral difficulties at 4 years old: moderation by family risk characteristics. Developmental Psychology, 44, 155-168.

Cummings, M. E., \& Davies, P. T. (1994). Maternal depression and child development. Journal of Child Psychology and Psychiatry, $35,73-112$.

Davis, E. P., Snidman, N., Wadhwa, P. D., Glynn, L. M., Schetter, C. D., \& Sandman, C. A. (2004). Prenatal maternal anxiety and depression predict negative behavioral reactivity in infancy. Infancy, 6, 319-331.

Dennis, C.-L., \& Ross, L. (2006). Women's perceptions of partner support and conflict in the development of postpartum depressive symptoms. Journal of Advanced Nursing, 56, 588-599.

Dickstein, S., Seifer, R., Hayden, C. L., Schiller, M., Sameroff, J. A., Keitner, G., et al. (1998). Levels of family assessment: II. Impact of maternal psychopathology on family functioning. Journal of Family Psychology, 12, 23-40.

DiPietro, J. A., Novak, M. F. S. X., Costigan, K. A., Atella, L. D., \& Reusing, S. P. (2006). Maternal psychological distress during pregnancy in relation to child development at age two. Child Development, 77, 573-587.

Du Rocher Schudlich, T. D., Youngstrom, E. A., Calabrese, J. R., \& Findling, R. L. (2008). The role of family functioning in bipolar 
disorder in families. Journal of Abnormal Child Psychology, 36, 849-863.

Ewell Foster, C. J., Garber, J., \& Durlak, J. A. (2008). Current and past maternal depression, maternal interaction behaviors and children's externalizing and internalizing symptoms. Journal of Abnormal Child Psychology, 36, 527-537.

Fergusson, D. M., Horwood, L. J., \& Lynskey, M. T. (1992). Family change, parental discord and early offending. Journal of Child Psychology and Psychiatry, 33, 1059-1075.

Field, T. (1995). Infants of depressed mothers. Infant Behavior \& Development, 18, 1-13.

Field, T., Healy, B., Goldstein, S., \& Guthertz, M. (1990). Behaviorstate matching and synchrony in mother-infant interactions of nondepressed versus depressed dyads. Developmental Psychology, 26, 7-14.

Forehand, R., Biggar, H., \& Kotchick, B. A. (1998). Cumulative risk across family stressors: short- and long-term effects for adolescents. Journal of Abnormal Child Psychology, 26, 119-128.

Gardner, F., \& Shaw, D. S. (2008). Behavioral problems of infancy and preschool children (0-5). In M. Rutter, D. Bishop, D. Pine, S. Scott, J. Stevenson, E. Taylor, \& A. Thapar (Eds.), Rutter's child and adolescent psychiatry (pp. 882-893). Oxford: Blackwell.

Gitau, R., Fisk, N. M., \& Glover, V. (2001). Maternal stress in pregnancy and its effect on the human foetus: an overview of research findings. Stress, 4, 195-203.

Glover, V., \& O'Connor, T. G. (2002). Effects of antenatal stress and anxiety: implications for development and psychiatry. The British Journal of Psychiatry, 180, 389-391.

Hay, D. F., Pawlby, S., Waters, C. S., \& Sharp, D. (2008). Antepartum and postpartum exposure to maternal depression: different effects on different adolescent outcomes. Journal of Child Psychology and Psychiatry, 49, 1079-1088.

Ingoldsby, E. M., Shaw, D. S., Owens, E. B., \& Winslow, E. B. (1999). A longitudinal study of interparental conflict, emotional and behavioral reactivity, and preschoolers' adjustment problems among low-income families. Journal of Abnormal Child Psychology, 27, 343-356.

Johnson, J. G., Cohen, P., Kasen, S., Smailes, E., \& Brook, J. S. (2001). Association of maladaptive parental behavior with psychiatric disorder among parents and their offspring. Archives of General Psychiatry, 58, 453-460.

Kim-Cohen, J., Moffitt, T. E., Taylor, A., Pawlby, S. J., \& Caspi, A. (2005). Maternal depression and children's antisocial behavior: nature and nurture effects. Archives of General Psychiatry, 62, $173-181$

Leblanc, N., Boivin, M., Dionne, G., Brendgen, M., Vitaro, F., Tremblay, R. E., et al. (2008). The development of hyperactiveimpulsive behaviors during the preschool years: the predictive validity of parental assessments. Journal of Abnormal Child Psychology, 36, 977-987.

Little, T. D., Jones, S. M., Henrich, C. C., \& Hawley, P. H. (2003). Disentangling the "whys" from the "whats" of aggressive behavior. International Journal of Behavioral Development, 27, 122-133.

Magnus, O., Irgens, L. M., Haug, K., Nystad, W., Skjærven, R., Stoltenberg, C., et al. (2006). Cohort profile: the Norwegian mother and child cohort study. International Journal of Epidemiology, 35, $1146-1150$

Mathiesen, K. S., \& Tambs, K. (1999). The EAS temperament questionnaire: factor structure, age trends, reliability, and stability in a Norwegian sample. Journal of Child Psychology and Psychiatry, 35, 431-439.

McDonald, R. P., \& Ho, R. M. (2002). Principles and practice in reporting structural equation analysis. Psychological Methods, 7, 64-82.
McIntosh, D. E., Mulkins, R. S., \& Dean, R. S. (1995). Utilization of perinatal risk indicators in the differential diagnosis of ADHD and UADD. The International Journal of Neuroscience, 81, $35-46$.

Muthén, L. K., \& Muthén, B. O. (2007). Mplus user's guide (5th ed.). Los Angeles: Muthén \& Muthén.

Nilsen, M. R., Vollset, S. E., Gjessing, H. K., Skjærven, R., Melve, K. K., Schreuder, P., et al. (2009). Self-selection and bias in a large prospective pregnancy cohort in Norway. Paediatric and Perinatal Epidemiology, 23, 597-608.

Nohr, E. A., Frydenberg, M., Henriksen, T. B., \& Olsen, J. (2006). Does low participation in cohort studies include bias? Epidemiology, 17, 413-418.

O'Connor, T. G., Heron, J., Golding, J., Beveridge, M., \& Glover, V. (2002). Maternal antenatal anxiety and children's behavioural/ emotional problems at 4 years: report from the avon longitudinal study of parents and children. The British Journal of Psychiatry, 180, 502-508.

Pedersen, S., \& Revenson, T. A. (2005). Parental illness, family functioning, and adolescent well-being: a family ecology framework to guide research. Journal of Family Psychology, 19, 404-419.

Phares, V. (1997). Accuracy of informants: do parents think that mother knows best? Journal of Abnormal Child Psychology, 25, 165-171.

Rahman, A., Bunn, J., Lovel, H., \& Creed, F. (2007). Association between antenatal depression and low birthweight in a developing country. Acta Psychiatrica Scandinavica, 115, 481-486.

Romano, E., Tremblay, R. E., Farhat, A., \& Côtè, S. (2006). Development and prediction of hyperactivity symptoms from 2 to 7 years in a population-based sample. Pediatrics, 117, 2101-2110.

Sameroff, A. J. (1998). Environmental risk factors in infancy. Pediatrics, 102, 1287-1292.

Schneider, M. L., Moore, C. F., \& Roberts, A. D. (2001). Prenatal stress alters early neurobehavior, stress reactivity and learning in non-human primates: a brief review. Stress, 4, 183-193.

Talge, N. M., Neal, C., \& Glover, V. (2007). Antenatal maternal stress and long-term effects on child neurodevelopment: how and why? Journal of Child Psychology and Psychiatry, 48, 245-261.

Tambs, K., \& Moum, T. (1993). How well can a few questionnaire items indicate anxiety and depression? Acta Psychiatrica Scandinavica, $87,364-367$.

Tomarken, A. J., \& Waller, N. G. (2005). Structural equation modelling: strengths, limitations and misconceptions. Annual Review of Clinical Psychology, 1, 31-65.

Van den Bergh, B. R. H., \& Marcoen, A. (2004). High antenatal maternal anxiety is related to ADHD symptoms, externalizing problems, and anxiety in 8- and 9-year-olds. Child Development, 75, 1085-1097.

van Zeijl, J., Mesman, J., Stolk, M. N., Alink, L. R. A., van Ijzendoorn, M. H., Bakermans-Kranenburg, M. J., et al. (2006). Terrible ones? Assessment of externalizing behaviors in infancy with the child behavior checklist. Journal of Child Psychology and Psychiatry, 47, 801-810.

Weinberg, M. K., \& Tronick, Z. E. (1998). Emotional characteristics of infants associated with maternal depression and anxiety. Pediatrics, 102, e1298-e1304.

Weinstock, M. (2008). The long-term behavioral consequences of prenatal stress. Neuroscience and Biobehavioral Reviews, 32, 1073-1086.

Welberg, L. A. M., \& Seckl, J. R. (2001). Prenatal stress, glucocorticoids and the programming of the brain. Journal of Neuroendocrineology, 13, 113-128.

Wolke, D., Waylen, A., Samara, M., Steer, C., Goodman, R., Ford, T., et al. (2009). Selective drop-out in longitudinal studies and nonbiased prediction of behaviour disorders. The British Journal of Psychiatry, 195, 249-256. 